\title{
Distribution of preferred ice crystal orientation determined from seismic anisotropy: Evidence from Jakobshavn Isbræ and the North Greenland Eemian Ice Drilling facility, Greenland
}

\author{
José A. Vélez ${ }^{1}$, Georgios P. Tsoflias ${ }^{2}$, Ross A. Black ${ }^{3}$, Cornelis J. Van der Veen ${ }^{4}$, and \\ Sridhar Anandakrishnan ${ }^{5}$
}

\begin{abstract}
Preferred crystal orientation fabrics (COFs) within an ice sheet or glacier are typically found from ice cores. We conducted experiments at the North Greenland Eemian Ice Drilling (NEEM) facility ice core location, where COF data were available at Jakobshavn Isbræ west Greenland, to test if COF can be determined seismically. We used observations of anisotropic seismic wave propagation on multioffset gathers and englacial imaging from a 2D reflection profile. Anisotropy analysis of the NEEM data yielded mean $c$-axes distributed over a conical region of $30^{\circ}$ to $32^{\circ}$ from vertical. No internal ice seismic reflectors were imaged. Direct COF measurements collected in the ice
\end{abstract}

core agreed with the seismic observations. At Jakobshavn Isbræ, we used a multioffset gather and a $2 \mathrm{D}$ reflection profile, but we lacked ice core data. Englacial reflectors allowed the determination of ice column interval properties. Anisotropy analysis found that the upper $1640 \mathrm{~m}$ of the ice column consisted of cold $\left(\approx-10^{\circ} \mathrm{C}\right)$ and mostly isotropic ice with $c$-axes distributed over a conical region of $80^{\circ}$ from vertical. The lower $300 \mathrm{~m}$ of the ice column was characterized by warm $\left(>-10^{\circ} \mathrm{C}\right)$ ice with COF. These observations were consistent with complex ice fabric development and temperature estimations over the same region of Jakobshavn Isbræ. This study demonstrated that the ice sheet and glacier ice anisotropy information can be gained from seismic field observations.

\section{INTRODUCTION}

Preferred ice crystal orientation, also known as the crystal orientation fabric (COF), is well-known from ice core studies of glaciers and ice sheets. COF was first documented in the Byrd Station ice core by Gow et al. (1968) showing how ice crystal $c$-axes statistically orient more vertically with increasing depth for the area of study. In addition to vertical loading, COF results from stresses induced by ice flow (Gow and Williamson, 1976, U.S. Army Cold Regions Research and Engineering Laboratory, report 76 35; Gow et al., 1976; Hooke, 1981). Bennet (1968) shows that COF is related to ultrasonic P-wave anisotropy. Dahl-Jensen (1985) shows that glacial ice with preferred crystal orientation is three times more de- formable than ice with randomly oriented crystals, and it can influence the flow behavior of glaciers and ice sheets (Van der Veen and Whillans, 1994). COF measurements are typically obtained from ice cores and are thus very limited and mostly constrained to areas with little ice flow. Improving our knowledge of the extent of COF layers within the ice sheets would help to assess their effects on large-scale ice flow. Here, we use seismic surveys to interpret the vertical distribution of ice fabric, which allows assessment of the area of fabric extent and how it might vary with depth.

Seismic waves in ice propagate up to $5 \%$ faster along the $c$-axis than perpendicular to it (Bennett, 1968; Bentley, 1971; Röthlisberger, 1972, U.S. Army Cold Regions Research and Engineering Laboratory, Technical report, monograph 11-A2a.). Bennett (1968)

\footnotetext{
Manuscript received by the Editor 6 March 2015; revised manuscript received 5 October 2015; published online 4 January 2016.

${ }^{1}$ The University of Kansas, Department of Geology, Center for Remote Sensing of Ice Sheets, Lawrence, Kansas, USA and Chevron Energy, Houston, Texas, USA. E-mail: jvelez@chevron.com.

${ }^{2}$ The University of Kansas, CReSIS and Department of Geology, Lawrence, Kansas, USA. E-mail: tsoflias@ku.edu

${ }^{3}$ The University of Kansas, Department of Geology, Lawrence, Kansas, USA. E-mail: black@ku.edu.

${ }^{4}$ The University of Kansas, Department of Geography, Center for Remote Sensing of Ice Sheets, Lawrence, Kansas, USA. E-mail: cjvdv@ku.edu.

${ }^{5}$ Pennsylvania State University, Department of Geosciences, University Park, Pennsylvania, USA. E-mail: sxa17@psu.edu.

(C) 2016 Society of Exploration Geophysicists. All rights reserved.
} 
investigates the propagation of $\mathrm{P}$-waves through single ice crystals and concludes that ice comprising layers with preferred crystal orientations can be treated as a transversely isotropic (TI) medium. Blankenship and Bentley (1987) develop a method, based on the common midpoint (CMP) seismic measurements and the anisotropic properties of single ice crystals, to estimate the mean $c$-axis ice crystal orientation within the ice column. Blankenship and Bentley (1987) demonstrate their method at Dome C Antarctica, but given the lack of an ice core at the time, a direct comparison between COF measurements and the seismic observations was not possible. Their interpretation of a single maxima fabric from the multioffset and multiazimuth CMP seismic experiment was proven accurate from direct ice core COF measurements published more than two decades later (Durand et al., 2009). In this paper, we test the Blankenship and Bentley (1987) seismic anisotropy analysis method at two distinctly different sites in Greenland. The first experiment was conducted at the North Greenland Eemian Ice Drilling (NEEM) facility at the northwest ice divide of the Greenland ice sheet (Figure 1), an area of no appreciable flow. The second experiment took place at the fast-flowing Jakobshavn Isbræ in west Greenland (Figure 2).

The NEEM facility was established to retrieve a complete ice core covering the early Eemian (approximately 115,000 years ago) and reconstruct the temperature record of that era (Dahl-Jensen et al., 2013). The NEEM ice core shows large variations in ice rheological properties (crystal sizes and COF patterns). Ice viscosities differ by a factor of 50-100 between the glacial and interglacial Eemian ice, allowing the glacial ice to deform more readily than the interglacial ice (Dahl-Jensen et al., 2013). Our seismic analysis shows good agreement with the NEEM ice core crystal measurements.

Jakobshavn Isbræ (Figure 2) is a fast flowing outlet glacier in Greenland with an annual mass loss of $30 \pm 4 \mathrm{Gt} / \mathrm{y}$ (Csatho et al., 2014). Satellite imagery and information from the lateral and terminal moraines suggest that Jakobshavn Isbræ has experienced significant changes in ice discharge. The unprecedented doubling of ice flow velocity from $6 \mathrm{~km} / \mathrm{a}$ in 1995 to more than $12 \mathrm{~km} / \mathrm{a}$ in 2005 (Rignot and Kanagaratnam, 2006; Joughin et al., 2012) is sustained today. Given the importance of Jakobshavn Isbræ to

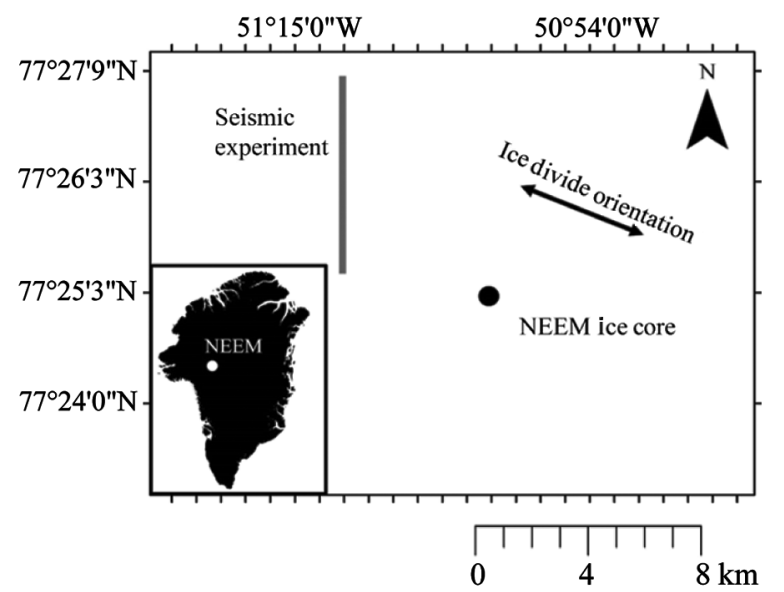

Figure 1. Location of seismic experiment near the NEEM ice core and orientation of the ice divide. the stability of the Greenland ice sheet, it is important to understand the controls of its recent behavior (e.g., Thomas, 2004; Van der Veen et al., 2011). Our experiment at Jakobshavn Isbræ (Figure 2) coincided with a 10-km seismic reflection profile (Horgan et al., 2008) that revealed englacial horizons in the lower portion (1648-1740-m depth) of the 1950-m-thick ice column. Horgan et al. (2008) suggest that the englacial reflectivity resulted from COF. We have adapted the Blankenship and Bentley (1987) method to detect zones of preferred ice crystal orientation within the ice column (as opposed to estimate mean crystal orientation for the entire column) and to account for effects of ice temperature on seismic wave propagation. We find that the bottom $300 \mathrm{~m}$ of ice at Jakobshavn Isbræ is characterized by preferred ice crystal orientation.

\section{BACKGROUND THEORY}

Theoretical anisotropic wave propagation is not commonly discussed in seismic cryosphere studies. Therefore, we briefly review the method developed by Blankenship and Bentley (1987), also discussed by Bennett (1968) and Blankenship (1982).

In linearly elastic materials, each component of stress linearly depends on every component of strain (Nye, 1957). The theory of elasticity for solid anisotropic bodies uses the generalized Hooke's law as follows:

$$
P_{i j}=C_{i j m n} \varepsilon_{m n}
$$

where $P_{i j}$ represents nine components of stress, $\varepsilon_{m n}$ represents nine components of strain, and $C_{i j m n}$ represents a stiffness tensor that contains 81 elastic constants. Given the complexity, several tensor symmetries (e.g., isotropic, monoclinic, triclinic, cubic, orthorhombic, and TI) are commonly used to describe the stiffness and wave velocity. These symmetries are distinguished by the form of their tensor (Tsvankin, 2005).

Bennett (1968) shows that the type of anisotropy characteristic of hexagonal crystals, such as ice, is similar to that of the layered media. A medium of this type is known as TI: "TI is the simplest anisotropic case of broad geophysical applicability, it has one distinct direction (usually, but not always, vertical), whereas the other

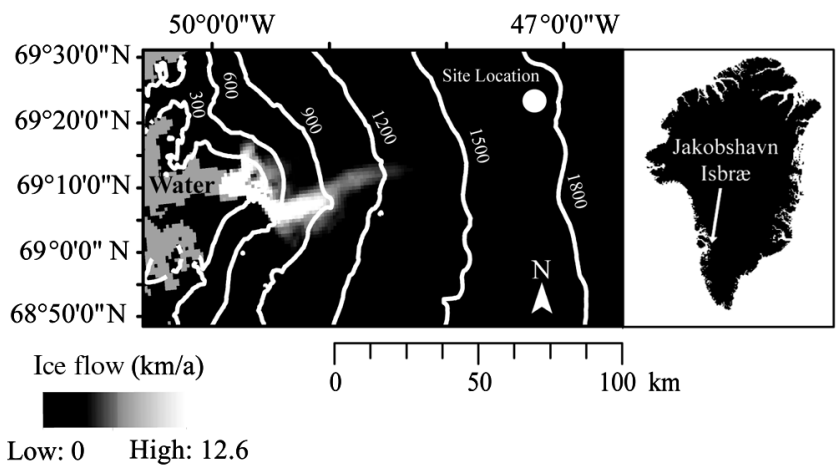

Figure 2. Location map of the Jakobshavn Isbræ study area. The position of the seismic experiment is marked by a circle. Ice surface elevation in meters is shown by contours (elevation data provided by CReSIS). The ice flow velocity from Joughin et al. (2010) is plotted in a logarithmic scale. 
two directions are equivalent to each other" (Thomsen, 1986). As a result, the elastic properties only vary as a function of the angle from the vertical, i.e., the angle of incidence. The elastic properties are radially symmetric with respect to a fixed axis of symmetry. In the case of layered media, the axis of symmetry is normal to the layering. Therefore, if an ice column is completely composed of ice with COF, the elastic properties would be symmetrically normal to the $c$-axis (Bennett, 1968).

The TI tensor contains five independent elastic constants. Bennett (1968) determines five elastic constants for single ice crystals obtained from the Mendenhall Glacier in Alaska (ice temperature: $-10^{\circ} \mathrm{C}$ ) from laboratory ultrasonic measurements. Using the elastic constants, Bennett (1968) models the mean slowness (inverse of velocity) of ice crystals at $-10^{\circ} \mathrm{C}$ by assuming that the crystallographic $c$-axes were spaced evenly along a solid cone of semiapex angles $I$ with radial symmetry about the $z$-axes (Figure 3 ). The geometry of the solid cone is frequently observed in core measurements collected in ice sheets (Blankenship, 1982) in which small $I$ values (closed cone) represent single-maxima $\mathrm{COF}$, and large $I$ values represent random ice crystal orientation. The reconstruction of the slowness surface (i.e., the surface of wave constant velocity) is based on $\sigma$, which represents the angle between the axis of symmetry $z$ and the direction of wave propagation $\mathbf{S}$ (Figure 3). The expression for mean slowness was obtained by spatially averaging the slowness contribution of each single ice crystal orientation as a function of $\sigma$.

According to Bennett (1968), the expression of a slowness surface on a solid cone for polycrystalline ice at $-10^{\circ} \mathrm{C}$ is given by the following equation:

$$
\mathbf{S}(\sigma, I) \approx A+B \cos 2 \sigma+C \cos 4 \sigma
$$

where

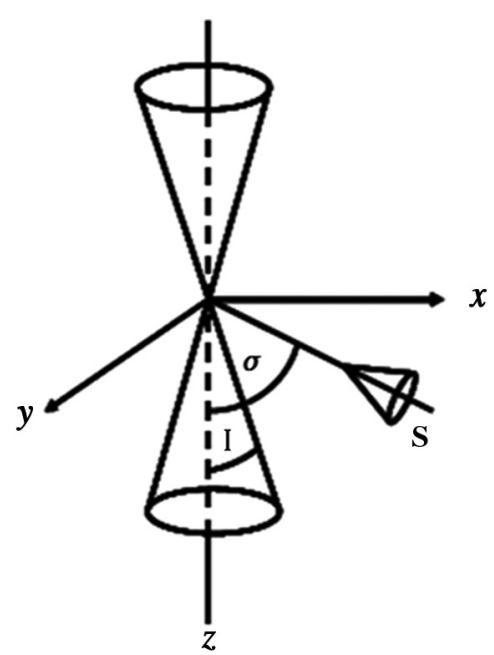

Figure 3. Schematic representation of a conical $c$-axes distribution $I$ along with the impinging wavefield $\mathbf{S}$ at an angle $\sigma$ (after Blankenship and Bentley, 1987).

$$
\begin{aligned}
A & =\left\{a-\frac{1}{3} b-\frac{1}{15} c\right\}+\frac{1}{6}\left\{b-\frac{23}{20} c\right\}\left(\cos I+\cos ^{2} I\right) \\
& +\frac{9}{40} c\left(\cos ^{3} I+\cos ^{4} I\right), \\
B & =\frac{1}{2}(b-c)\left(\cos I+\cos ^{2} I\right)+\frac{1}{2} c\left(\cos ^{3} I+\cos ^{4} I\right),
\end{aligned}
$$

and

$$
C=-\frac{3}{8} c\left(\cos I+\cos ^{2} I\right)+\frac{7}{8} c\left(\cos ^{3} I+\cos ^{4} I\right) .
$$

The coefficients $a, b$, and $c$ are empirically derived ( $a=$ $256.28 \mu \mathrm{s} / \mathrm{m}, b=-5.08 \mu \mathrm{s} / \mathrm{m}$, and $c=-5.92 \mu \mathrm{s} / \mathrm{m}) ; \sigma$ is the angle between the axis of symmetry $z$ and the direction of wave propagation $\mathbf{S}$; and $I$ represents the ice crystal orientation in a conical distribution (Figure 3). In Figure 4, equation 2 is used to model the variation of slowness as a function of $\sigma$ for multiple $I$, where $I=90^{\circ}$ represents perfectly random ice crystal orientation (no variation of slowness as a function of sigma: solid line), and $I=0^{\circ}$ represents single-maxima $\mathrm{COF}$ (maximum variation of slowness as a function of sigma: triangles).

The velocity surface can be easily constructed for an ice column from a CMP seismic gather if the local bed geometry is known. The slowness surface as a function of $\sigma$ can also be determined (Blankenship and Bentley, 1987). By comparing the modeled slowness surfaces (e.g., Figure 4) and the slowness surface observed from a CMP seismic experiment, it is possible to determine if COF is present in the area of study.

\section{FIELD EXPERIMENTS}

\section{NEEM experiment}

We acquired a long-offset, pseudo-CMP active-source seismic gather $6.5 \mathrm{~km}$ north of the NEEM ice core location (Figure 1) to compare anisotropy observations directly with COF information from the ice core.

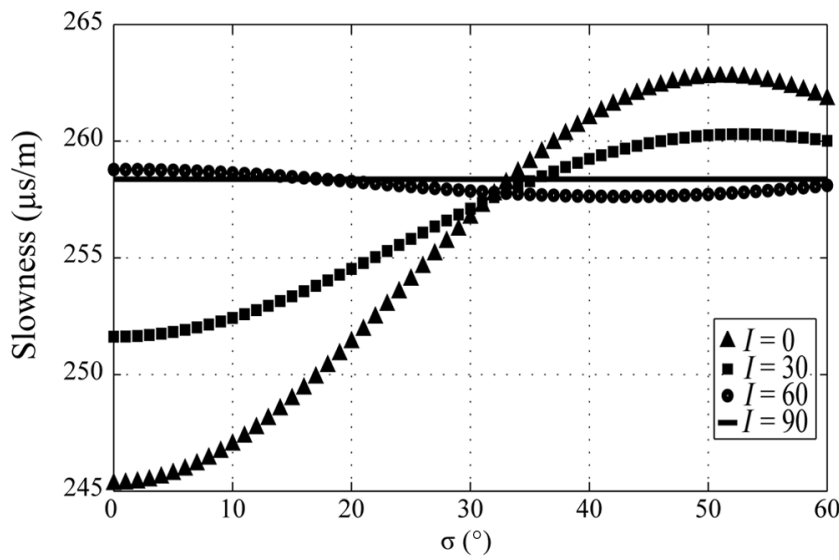

Figure 4. Model of slowness as a function of the wavefield angle to the ice crystal axis of symmetry $(\sigma)$ for varying conical $c$-axis distribution (I) (after Bennett, 1968). 


\section{NEEM data acquisition}

The seismic experiment at NEEM was conducted in June 2012, and the location was selected to avoid interference with the site's aircraft runway. Three source shots with increasing offset were recorded in a pseudo-CMP configuration. The receiver line was $1900 \mathrm{~m}$ long with ninety-six $100 \mathrm{~Hz}$ geophones at $20 \mathrm{~m}$ spacing. The first shot offset range was $20-1920 \mathrm{~m}$ to obtain near-offset coverage at small incidence angles. For shots two and three, source and receiver locations were rolled in opposite directions resulting in the offset ranges of 1940-3840 and 3860-5760 m, respectively. Shot records two and three provided wide-angle, far-offset coverage of approximately twice the thickness of the ice column. The seismic source was $0.5 \mathrm{~kg}$ of pentaerythritol tetranitrate (PETN) placed in shotholes buried $10 \mathrm{~m}$ below the surface. Data were recorded for $8 \mathrm{~s}$ with a 0.25 -ms sampling interval using four 24-channel seismographs. Shot triggering and recording was enabled by global positioning system (GPS) synchronization.

\section{NEEM experiment results}

Data from shot one are shown in Figure 5 with a band-pass filter of $80-350 \mathrm{~Hz}$ to increase the signal-to-noise ratio and facilitate picks for the base of ice (bed) interface. We used an average seismic velocity for ice of $3840 \mathrm{~m} / \mathrm{s}$ NMO correct the shot gather based on an ice temperature of $-14^{\circ} \mathrm{C}$ (Rasmussen et al., 2013), and the relationship for temperature correction for P-wave velocity (Kohnen, 1974). As seen in Figure 5b, the bed reflection is flattened for the first two-thirds of the offset range of the shot gather, but moveout remains at far offsets from approximately 1200 to $1920 \mathrm{~m}$. This residual moveout (reflectors at far offsets exhibiting later arrival times) may be the result of bed topography or a decrease in seismic velocity caused by the anisotropy in the ice column.

The Blankenship and Bentley (1987) analysis requires bed geometry information (depth and dip angle). Assuming horizontal geometry and using time picks extracted from all three shots, the slowness surface varied from 252 to $260 \mu \mathrm{s} / \mathrm{m}$ with $\sigma$ values ranging from $0^{\circ}$ to $48^{\circ}$ (Figure 6). Modeled slowness curves are also

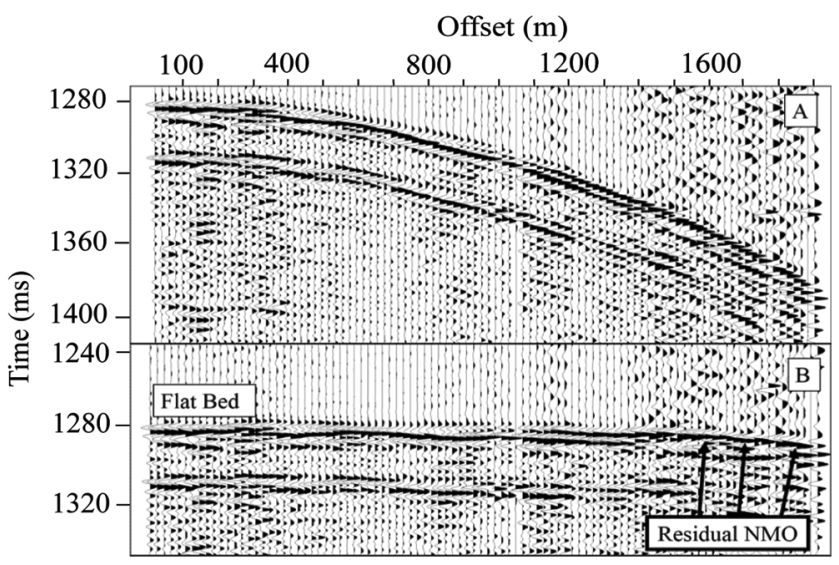

Figure 5. Shot one of near-offset data displayed with a band-pass filter of 80-350 Hz: (a) raw-filtered data and (b) NMO-corrected data using ice velocity of $3840 \mathrm{~m} / \mathrm{s}$. The upper reflection $(1280 \mathrm{~ms})$ is interpreted to be from the base of ice/top of till interface. The lower reflection $(1310 \mathrm{~ms})$ is interpreted as the top of the bedrock. shown for $I=30^{\circ}$ and $I=32^{\circ}$. Near-offset data with $\sigma$ values of approximately up to $12^{\circ}$ are bounded by model curves for $I=$ $30^{\circ}$ and $I=32^{\circ}$. Longer offset slowness analysis results closely match the model $I=30^{\circ}$ (Figure 6).

\section{NEEM experiment discussion}

COF measurements are commonly displayed in terms of $c$-axis orientation and presented in Schmidt plots (Figure 7). Schmidt plots (Ferrick and Claffey, 1992, U.S. Army Corps of Engineers Cold Regions Research and Engineering Laboratories, report 92-1.) display the relative concentration of $c$-axes in one dimension by projecting in the center of the plot the angle between the crystallographic $c$-axis and the direction normal to the surface.

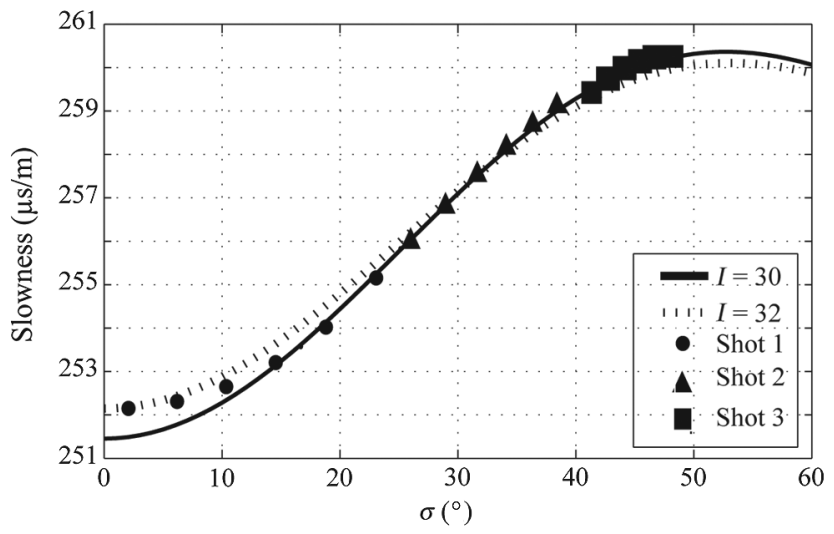

Figure 6. Results of the Blankenship and Bentley (1987) analysis applied to the NEEM site data under the assumption of a horizontal bed. The symbols indicate field observations, and the lines indicate slowness models for varying $I$ angles.

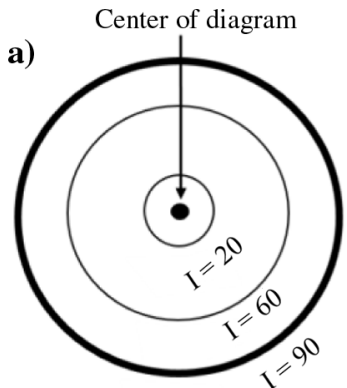

b)
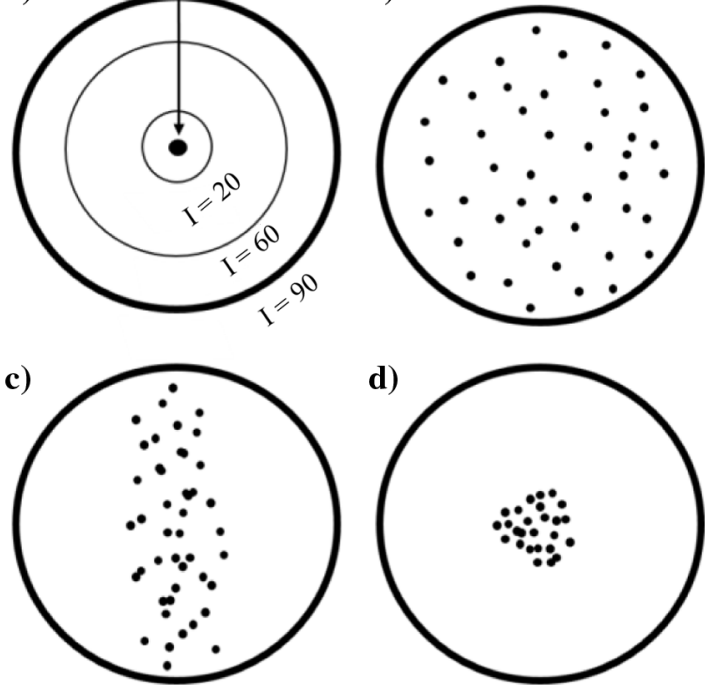

Figure 7. (a) Here, $I$ angles of $20^{\circ}, 60^{\circ}$, and $90^{\circ}$ drawn as concentric circles for an ice $c$-axis conical distribution displayed in a Schmidt plot. Examples of (b) random, (c) disk, and (d) single-maxima COF (based on Van der Veen and Whillans, 1994). 
The orientation distribution determines the type of COF (e.g., random, single maxima, and disk fabric; refer to Figure 7), and it is used to infer the stresses acting in an ice column (Van der Veen and Whillans, 1994). Measurements at NEEM confirmed COF for approximately $76 \%$ of the ice column (600-2500 m depth) with $16 \%$ characterized by single maxima COF and $60 \%$ by a disk ice fabric (Montagnat et al., 2014). The transition between random ice and the disk fabric is gradual, changing over an interval approximately $400 \mathrm{~m}$ thick. The same behavior is observed in the transition between the disk fabric and a single maxima over an interval of approximately $220 \mathrm{~m}$. The seismic data reveal no internal horizons. This lack of seismic reflections is interpreted to result from a gradational COF transition, occurring over hundreds of meters, and the relatively shorter wavelengths (approximately $20 \mathrm{~m}$ ) of the seismic data.

Although ice measurements are not given in the form of $I$ values, based on the eigenvalues published by Montagnat et al. (2014), I values in the range of $15^{\circ}-25^{\circ}$ should be expected for the bottom $60 \%$ of the ice column. The seismic line was oriented oblique to the northwest-southeast-trending ice divide, at approximately $50^{\circ}$ (Figure 2). Numerical models of ice deformation show that ice subjected to extensional forces (such as at an ice divide) tends to generate a disk fabric in which the disk is oriented perpendicular to the extensional forces (Van der Veen and Whillans, 1994). Given the extensional stress at NEEM, the disk fabrics observed at the area of study should be oriented parallel to the ice divide. As a result, the seismic line is oriented obliquely to the anisotropy of the disk, and the variation of seismic velocity as a function of angle of incidence may not follow a single model of $I$.

Our analysis shows that the slowness model of $I=30^{\circ}$ fits the mid and far offsets, whereas $I=32^{\circ}$ fits the near offsets. The oblique seismic line observed an apparent seismic anisotropy less than the real maximum anisotropy of ice that would result in greater $I$ values. Furthermore, the $I$ estimates are averaged over the entire propagation path, including shallow isotropic ice $\left(I=90^{\circ}\right)$ and deeper anisotropic ice. The effect of propagation through isotropic ice (24\% of travel path at NEEM) results in higher $I$ values than the COF measurements at the ice core. Therefore, our mean COF $I$ estimates of $30^{\circ}$ and $32^{\circ}$ agree well with the eigenvalues obtained in the NEEM ice core (Montagnat et al., 2014).

Seismic studies have associated the presence of internal ice reflections with sharp transitions in COF (e.g., Horgan et al.,

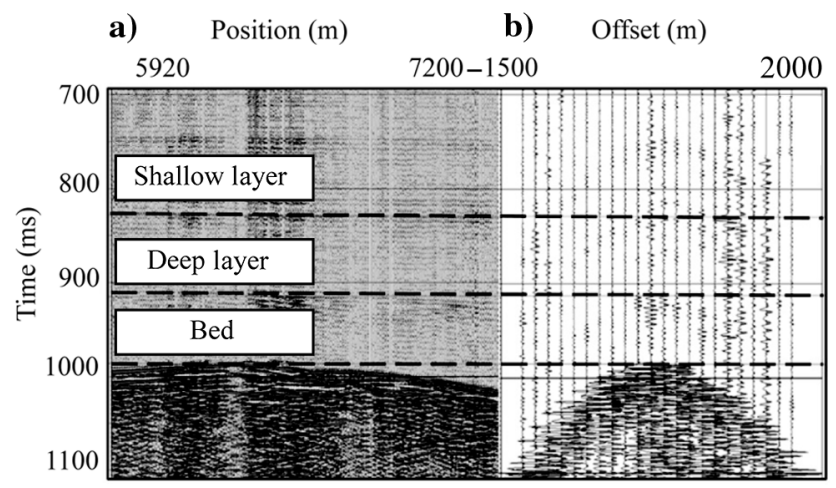

Figure 8. (a) Section of the 2D seismic profile collected by Horgan et al. (2008) along flow of Jakobshavn Isbræ and (b) multioffset receiver gather coincident with the $2 \mathrm{D}$ profile.
2008, 2011; Hofstede et al., 2013). However, the experiment performed at NEEM shows that the lack of internal ice reflectivity does not necessarily indicate the absence of COF. The absence of abrupt COF transitions at NEEM is consistent with the location of the site in the interior of the Greenland ice sheet compared with COF patterns that may be expected at faster flowing regions.

\section{Jakobshavn Isbræ experiment}

\section{Jakobshavn data acquisition}

The seismic experiments at Jakobshavn Isbræ were conducted in the summer of 2007 approximately $100 \mathrm{~km}$ away from the mouth of Jakobshavn Isbræ. The ice was moving approximately $100 \mathrm{~m} / \mathrm{a}$ (Figure 2). Two data sets were collected simultaneously in an area in which no nearby ice core information was available. The first data set (Horgan et al., 2008) consisted of a $10 \mathrm{~km} 2 \mathrm{D}$ seismic reflection profile aligned along the ice flow direction. The second data set, used in this study, is a receiver gather acquired with a stationary array of eight $100-\mathrm{Hz}$ vertical geophones at $0.5 \mathrm{~m}$ spacing. Data were recorded for $8 \mathrm{~s}$ using a $0.5 \mathrm{~ms}$ sampling interval. The source for both data sets was $500 \mathrm{~g}$ of PETN at a depth of $10 \mathrm{~m}$ below the surface. Simultaneous shot triggering and data recording were enabled by GPS synchronization.

Source locations were oriented along ice flow direction, spaced $160 \mathrm{~m}$ at offsets ranging from -1760 to $+1600 \mathrm{~m}$. The resulting receiver gather consists of 22 variable-angle records corresponding to incidence angles at the base of ice ranging from $-24^{\circ}$ to $+20^{\circ}$. The data from all eight geophones were stacked for each shot, and a $150-\mathrm{Hz}$ low-pass filter was applied to increase the signal-tonoise ratio.

\section{Jakobshavn experiment results}

The seismic profile presented by Horgan et al. (2008) imaged the bed geometry, and distinct englacial horizons, interpreted to be the result of COF. Figure 8 shows a $1.3-\mathrm{km}$ section of the profile coincident with the 22-trace receiver gather. The reflection horizon from the bed is at approximately $1000 \mathrm{~ms}$, and two englacial horizons are identified as "shallow layer" at approximately $820 \mathrm{~ms}$, and "deep layer" at approximately $910 \mathrm{~ms}$ (Figure 8). Unlike the analysis

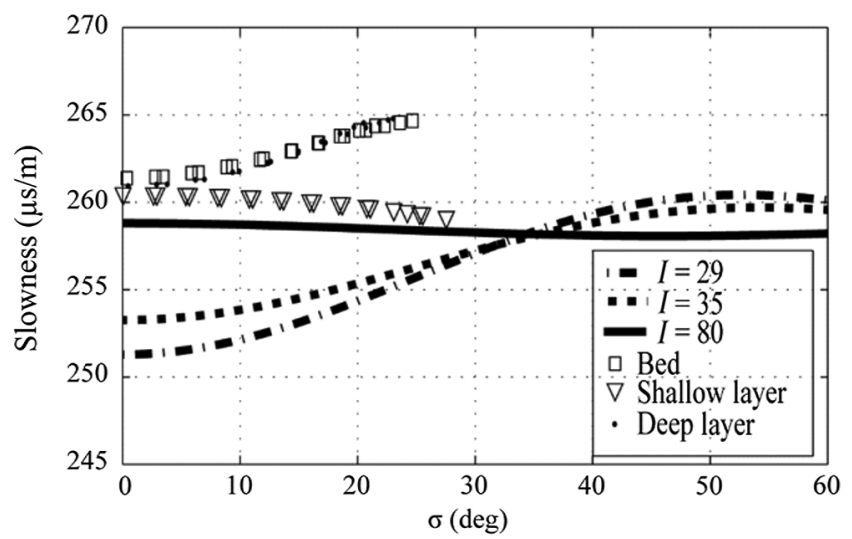

Figure 9. Mean ice crystal orientation analysis results of three interpreted horizons from the multioffset data. The symbols indicate field observations, and the lines indicate slowness models for varying $I$ angles. 
at NEEM and by Blankenship and Bentley (1987) in which mean seismic anisotropy was determined over the entire ice column by deriving slowness of the bed, englacial reflectivity allows slowness observations within the ice and the determination of localized anisotropy. Depth and dip angles for the three horizons (shallow and deep englacial reflectors and the bed) were extracted from the reflection profile at each trace location of the receiver gather data and used in the slowness versus $\sigma$ analysis.

Figure 9 shows the results of field data analysis (symbols) and model curves for varying $I$ values. The slowness solutions from field data are bulk-shifted relative to the model curves and fall outside the range of plausible slowness versus $\sigma$ values. The model curves were developed for a constant ice temperature of $-10^{\circ} \mathrm{C}$ (Bennett, 1968). We attribute this shift in velocity to ice temperature variability, which would affect seismic velocity and attenuation (e.g., Kohnen, 1974; Tonn, 1991; Dasgupta and Clark, 1998). Temperature decreases (warm ice) or increases (cold ice) P-wave velocity. At Jakobshavn Isbræ, seismic attenuation observations and ice core measurements show a temperate basal ice layer within the lowermost $300 \mathrm{~m}$ of the ice column (Iken et al., 1993; Peters et al., 2012). Therefore, we correct for temperature effects in our anisotropy analysis by determining bulk-shift velocity correction factors based on the fit of the observed data to the slowness models. The sign of each velocity correction factor provides relative information about the internal temperature of the ice column, with a positive velocity correction factor indicating ice warmer than $-10^{\circ} \mathrm{C}$ and a negative correction factor indicating ice colder than $-10^{\circ} \mathrm{C}$. Figure 9 indicates that positive velocity shifts of the field observations are needed to match the model curves, and therefore, ice warmer than $-10^{\circ} \mathrm{C}$ should be present in the region of internal ice reflectivity and the bed, which is consistent with the temperate basal ice at Jakobshavn.

Figure 10 displays temperature-corrected slowness observations along with the corresponding model curves. Our analysis reveals that the shallower internal layer slowness varies from 259 to $258 \mu \mathrm{s} / \mathrm{m}$, which represents $0.46 \%$ anisotropy corresponding to $I=80^{\circ}$ using a velocity correction factor of $+30 \mathrm{~m} / \mathrm{s}$. The deep layer varies from 251 to $256 \mu \mathrm{s} / \mathrm{m}$. This accounts for $2 \%$ of slowness anisotropy, which correlates with a modeled ice crystal orien-

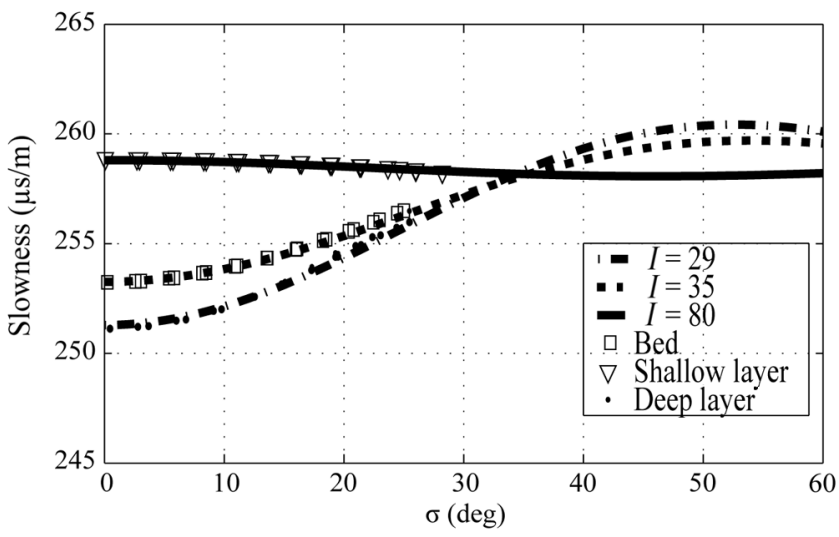

Figure 10. Mean ice crystal orientation analysis results of three interpreted horizons from the multioffset data with velocity corrections applied to account for ice temperature effects. The symbols indicate field observations, and the lines indicate slowness models for varying $I$ angles. tation of $I=29^{\circ}$ with a velocity correction factor of $+125 \mathrm{~m} / \mathrm{s}$. Finally, the bed slowness changes from 253 to $257 \mu \mathrm{s} / \mathrm{m}$ accounting for $1.33 \%$ variation in velocity and $I=35^{\circ}$ with a velocity correction factor of $+90 \mathrm{~m} / \mathrm{s}$ (Figure 10).

The small correction factor of $30 \mathrm{~m} / \mathrm{s}$ for the shallow layer suggests that the top $1640 \mathrm{~m}$ of the ice column is characterized by ice with a temperature close to $-10^{\circ} \mathrm{C}$, whereas the correction factors of $125 \mathrm{~m} / \mathrm{s}$ for the deep internal layer and $90 \mathrm{~m} / \mathrm{s}$ for the bed indicate warmer ice at the bottom $300 \mathrm{~m}$. This result strongly agrees with the temperature model for this area derived by Peters et al. (2012) using seismic attenuation.

\section{Jakobshavn experiment discussion}

The seismic anisotropy model developed by Bennett (1968) relates the slowness of ice at a temperature of $-10^{\circ} \mathrm{C}$ to ice crystal orientation $I$ and the angle with the direction of wave propagation $\sigma$ (Figure 3 ). The seismic ice velocity also depends on temperature (Kohnen, 1974). Therefore, the elastic moduli determined experimentally by Bennett (1968) depend on temperature. As a result, our analysis is affected by the ice column temperature, as well. Consequently, temperature affected our velocities but not anisotropy. Thus, the slowness variation with offset observed in the field data (Figures 9 and 10) results from preferred ice crystal orientation.

Using the velocity correction factors, our results suggest that the top $1640 \mathrm{~m}$ of ice is isotropic $\left(I=80^{\circ}\right)$, whereas the bottom $300 \mathrm{~m}$ is anisotropic (average $I=32^{\circ}$ ). However, multiazimuth data are necessary to capture the full radial extent of the velocity anisotropy. Given that the 2D multioffset data were collected along the flow direction of the glacier, the analysis would correspond only to the anisotropy along the 2D line, which does not necessarily represent the mean anisotropy in the ice column.

Based on the location of the test site, we reasonably assume that lateral drag is small and the main driving forces are basal drag and gravitational forces. Typically, in areas in which vertical shear is dominant, the near-surface ice is characterized by a random $c$-axis distribution, whereas the englacial and basal ice are characterized by a preferred ice crystal orientation (e.g., Alley, 1988; Budd and Jacka, 1989; Wang et al., 2002). Using an age-depth relationship (Funk et al., 1994), the impurity loading history of Greenland (Mayewski et al., 1993; O'Brien et al., 1995), Horgan et al. (2008) suggest that the low-frequency reflection at $910 \mathrm{~ms}$ (Figure 8 deep layer) corresponds to the bottom of the Younger Dryas stadial ice, characterized by predominantly vertical $c$-axes. Therefore, our results strongly agree with the observations made by Horgan et al. (2008). The presence of englacial reflectors in conjunction with short seismic wavelengths (approximately $25 \mathrm{~m}$ ) and the increase in anisotropy between the shallow and deep internal layers (Figure 10) suggest that the transition to anisotropic ice must occur within a short interval of a few meters, which correlates with the rapid transition $(<10 \mathrm{~m})$ observed between random and single maxima COF at the Dye- 3 ice core $500 \mathrm{~km}$ from our area (Herron et al., 1985).

As previously discussed, Bennett's (1968) model is based on single ice crystal ultrasonic measurements, and therefore it does not incorporate the complexity of seismic wave propagation through an ice sheet or glacier. In addition, our analysis is based on single-azimuth seismic data, which does not capture the full presence of the anisotropy of the ice column. Therefore, our $I$ values for each 
layer should be used to determine the presence of preferred ice crystal orientation and not to quantify the actual angle at which the ice crystals are oriented.

\section{CONCLUSIONS}

We have successfully analyzed the seismic wave slowness variability as a function of wave field angle with ice crystal orientation at the NEEM site to determine COF. We found a correlation between the slowness results and models of mean $c$-axes distributed over a conical region $I$ of $30^{\circ}-32^{\circ}$ from vertical for most of the area of study based on the assumption of a flat bed at a depth of $2540 \mathrm{~m}$. Near-offset versus far-offset slowness observations may fit slightly different $I$ models due to the variation of seismic velocity traveling through different parts of the disk ice fabric as the angle of incidence increases. Given the ice column properties of the area of study, we consider the mean $I$ angle of $30^{\circ}$ acceptable and confirm the utility of the anisotropy analysis method for single-azimuth data to detect preferred ice crystal orientation. However, because the angle at which the wavefront travels relative to the orientation of the disk fabric is not known, a direct one-to-one comparison between the seismic anisotropy analysis and the NEEM ice crystal data is not possible. The use of multiazimuthal data should substantially increase the robustness of the analysis, thus allowing the comparison between the mean ice crystal orientation based on the direct ice crystal measurements and the mean ice crystal orientation based on the seismic anisotropy analysis.

By adapting the anisotropy analysis method to account for velocity changes due to ice temperature and by examining slowness observations from three layers, it was possible to obtain information about the ice crystalline fabrics in the ice column of Jakobshavn Isbræ. The analysis for all three layers revealed that the slowness results match models of $I$ of $35^{\circ}, 29^{\circ}$, and $80^{\circ}$ with velocity correction factors of $+90,+125$, and $+30 \mathrm{~m} / \mathrm{s}$ for the bed, deep, and shallow layers, respectively. Therefore, we conclude that the top $1650 \mathrm{~m}$ is mostly isotropic at a temperature close to $-10^{\circ} \mathrm{C}$, whereas the bottom $300 \mathrm{~m}$ is temperate with the preferred ice crystal orientation.

The presence or absence of englacial reflectors also provides an insight into the nature of the transition between random and anisotropic ice. At NEEM, no reflectors were observed in the areas of transition between COF. This is attributed to the thickness of the transition zone of hundreds of meters resulting in a gradational interface. The englacial reflectors at Jakobshavn indicate an abrupt transition interval of a few meters. Importantly, although the presence of englacial reflectivity provides evidence of COF development, the absence of reflectivity does not exclude the presence of COF layers.

\section{ACKNOWLEDGMENTS}

This work was made possible by the National Science Foundation and CReSIS (grant no. ANT-0424589) at the University of Kansas in collaboration with Penn State Ice and Climate Exploration (L. Peters, K. Riverman, A. Muto, K. Christianson, and D. Voigt). We would like to express appreciation to J. P. Steffensen, D. Dahl-Jensen, and all the staff members at NEEM for their support in this investigation. Partial student funding for this investigation was provided by NASA's Harriet Jenkins Pre-Doctoral
Fellowship program. Finally, we would like to make a special mention of appreciation to A. Hoch for his support in this investigation.

\section{REFERENCES}

Alley, R. B., 1988, Fabrics in polar ice sheets: Development and prediction: Science, 240, 493-495, doi: 10.1126/science.240.4851.493.

Bennett, H. F., 1968, An investigation into velocity anisotropy through measurements of ultrasonic wave velocities in snow and ice cores from Greenland and Antarctica: Ph.D. thesis, University of Wisconsin-Madison.

Bentley, C. R., 1971, Seismic anisotropy of the West Antarctic ice sheet, in A. P. Crary, ed., Antarctic snow and ice studies II: American Geophysical Union Antarctic Research Series, 131-177.

Blankenship, D. D., 1982, P-wave anisotropy in the high polar ice of East Antarctica: M.S. thesis, University of Wisconsin-Madison.

Blankenship, D. D., and C. R. Bentley, 1987, The crystalline fabric of polar ice sheets inferred from seismic anisotropy: The physical basis of ice sheet modelling, in E. D. Waddington, and J. S. Walder, eds., International Association of Hydrological Sciences, 170, 17-28.

Budd, W. F., and T. H. Jacka, 1989, A review of ice rheology for ice sheet modeling: Cold Regions Science and Technology, 16, 107-144, doi: 10 $.1016 / 0165-232 X(89) 90014-1$.

Csatho, B., A. Schenk, C. J. Van der Veen, G. Babonis, K. Duncan, S. Rezvanbehbahanic, M. R. Van den Broeke, S. B. Simonsen, S. Nagarajan, and J. H. Van Angelen, 2014, Laser altimetry reveals complex pattern of Greenland Ice Sheet dynamics: Proceedings of the National Academies of Sciences, 111, 18478-18483, doi: 10.1073/pnas.1411680112.

Dahl-Jensen, D., 1985, Determination of the flow properties at dye 3, south Greenland, by bore-hole-tilting measurements and perturbation modeling: Journal of Glaciology, 31, 92-98

Dahl-Jensen, D., M. R. Albert, A. Aldahan, N. Azuma, D. Balslev Clausen, M. Baumgartner, A.-M. Berggren, M. Bigler, T. Binder, T. Blunier, J. C. Bourgeois, E. J. Brook, S. L. Buchardt, C. Buizert, E. Capron, J. Chappellaz, J. Chung, H. B. Clausen, I. Cvijanovic, S. M. Davies, P. Ditlevsen, O. Eicher, H. Fischer, D. A. Fisher, L. G. Fleet, G. Gfeller, V. Gkinis, S. Gogineni, K. Goto-Azuma, A. Grinsted, H. Gudlaugsdottir, M. Guillevic, S. B. Hansen, M. Hansson, M. Hirabayashi, S. Hong, S. D. Hur, P. Huybrechts, C. S. Hvidberg, Y. Iizuka, T. Jenk, S. J. Johnsen, T. R. Jones, J. Jouzel, N. B. Karlsson, K. Kawamura, K. Keegan, E. Kettner, S. Kipfstuhl, H. A. Kjær, M. Koutnik, T. Kuramoto, P. Köhler, T. Laepple, A Landais, P. L. Langen, L. B. Larsen, D. Leuenberger, M. Leuenberger, C. Leuschen, J. Li, V. Lipenkov, P. Martinerie, O. J. Maselli, V. Masson-Delmotte, J. R. McConnell, H. Miller, O. Mini, A. Miyamoto, M. Montagnat-Rentier, R. Mulvaney, R. Muscheler, A. J. Orsi, J. Paden, C. Panton, F. Pattyn, J.-R. Petit, K. Pol, T. Popp, G. Possnert, F. Prié, M. Prokopiou, A. Quiquet, S. O. Rasmussen, D. Raynaud, J. Ren, C. Reutenauer, C. Ritz, T. Röckmann, J. L. Rosen, M. Rubino, O. Rybak, D Samyn, C. J. Sapart, A. Schilt, A. M. Z. Schmidt, J. Schwander, S. Schüpbach, I. Seierstad, J. P. Severinghaus, S. Sheldon, S. B. Simonsen, J. Sjolte, A. M. Solgaard, T. Sowers, P. Sperlich, H. C. Steen-Larsen, K Steffen, J. P. Steffensen, D. Steinhage, T. F. Stocker, C. Stowasser, A. S. Sturevik, W. T. Sturges, A. Sveinbjörnsdottir, A. Svensson, J.-L. Tison, J. Uetake, P. Vallelonga, R.S.W. van de Wal, G. van der Wel, B. H. Vaughn, B. Vinther, E. Waddington, A. Wegner, I. Weikusat, J. W. C. White, F. Wilhelms, M. Winstrup, E. Witrant, E. W. Wolff, C. Xiao, and J. Zheng, 2013, Eemian interglacial reconstructed from a Greenland folded ice core: Nature, 493, 489-494, doi: 10.1038/nature11789.

Dasgupta, R., and R. A. Clark, 1998, Estimation of $Q$ from surface seismic reflection data: Geophysics, 63, 2120-2128, doi: 10.1190/1 .1444505 .

Durand, G., A. Svensson, A. Persson, O. Gagliardini, F. Gillet-Chaulet, A. Sjolte, M. Montagnat, and D. Dahl-Jensen, 2009, Evolution of the texture along the EPICA dome $\mathrm{C}$ ice core, in T. Hondoh, ed., Physics of ice core records II: Institute of Low Temperature Science, 68, 91-105.

Funk, M., K. A. Echelmeyer, and A. Iken, 1994, Mechanisms of fast flow in Jakobshavns Isbræ, west Greenland: Part II. Modeling of englacial temperatures: Journal of Glaciology, 40, 569-585.

Gow, A. J., H. T. Ueda, and D. E. Garfield, 1968, Antarctic ice sheet preliminary results of first core hole to bedrock: Science, 161, 1011-1013, doi: 10.1126/science.161.3845.1011.

Herron, L. S., C. C. Langway, and K. A. Brugger, 1985, Ultrasonic velocities and crystalline anisotropy in the ice core from dye 3, Greenland, in C. C. Langway, H. Oeschger, and W. Dansgaard, eds., Greenland ice core: Geophysics, geochemistry, and the environment: American Geophysical Union Geophysical Monograph Series, 23-31.

Hofstede, C., O. Eisen, A. Diez, D. Jansen, Y. Kristoffersen, A. Lambrecht, and C. Mayer, 2013, Investigating englacial reflections with vibro- and explosive-seismic surveys at Halvfarryggen ice dome, Antarctica: Annals of Glaciology, 54, 189-200, doi: 10.3189/2013AoG64A064. 
Hooke, R. L., 1981, Flow law for polycrystalline ice in glaciers: Comparison of theoretical predictions, laboratory data, and field measurements: Reviews of Geophysics, 19, 664-672, doi: 10.1029/RG019i004p00664.

Horgan, H. J., S. Anandakrishnan, R. B. Alley, P. G. Burkett, and L. E. Peters, 2011, Englacial seismic reflectivity: Imaging crystal-orientation fabric in West Antarctica: Journal of Glaciology, 57, 6396-6500, doi: 10 3189/002214311797409686.

Horgan, H. J., S. Anandakrishnan, R. B. Alley, L. E. Peters, G. P. Tsoflias, D. E. Voigt, and J. P. Winberry, 2008, Complex fabric development revealed by englacial seismic reflectivity: Jakobshavn Isbræ, Greenland: Geophysical Research Letters, 35, L10501, doi: 10.1029/2008GL033712.

Iken, A., K. Echelmeyer, W. Harrison, and M. Funk, 1993, Mechanisms of fast flow in Jakobshavn Isbrae, west Greenland; part I: Measurements of temperature and water level in deep boreholes: Journal of Glaciology, 39 $15-25$.

Joughin, I., B. Smith, I. Howat, and T. Scambos, 2010, MEaSUREs Greenland Ice Sheet Velocity Map from InSAR Data, Version 1. [NSIDC-0478.001/2008.12.01]: NASA National Snow and Ice Data Center Distributed Active Archive Center, doi: 10.5067/MEASURES/ CRYOSPHERE/nsidc-0478.001.

Joughin, I., B. E. Smith, I. M. Howat, D. Floricioiu, R. B. Alley, M. Truffer, and M. Fahnestock, 2012, Seasonal to decadal scale variations in the surface velocity of Jakobshavn Isbrae, Greenland: Observation and modelbased analysis: Journal of Geophysical Research, 117, doi: 10.1029/ 2011JF002110.

Kohnen, H., 1974, The temperature dependence of seismic waves in ice: Journal of Glaciology, 13, 144-147.

Mayewski, P. A., L. D. Meeker, S. Whitlow, M. S. Twickler, M. C. Morrison, R. B. Alley, P. Bloomfield, and K. Taylor, 1993, The atmosphere during the Younger Dryas: Science, 261, 195-197, doi: 10.1126/science.261 .5118 .195 .

Montagnat, M., N. Azuma, D. Dahl-Jensen, J. Eichler, S. Fujita, F. GilletChaulet, S. Kipfstuhl, D. Samyn, A. Svensson, and I. Weikusat, 2014 Fabric along the NEEM ice core, Greenland, and its comparison with GRIP and NGRIP ice cores: The Cryosphere, 8, 1129-1138, doi: 10 .5194/tc-8-1129-2014.

Nye, J. F., 1957, Physical properties of crystals: Oxford University Press.
O'Brien, S., P. Mayewski, L. Meeker, D. Meese, M. Twickler, and S. Whitlow, 1995, Complexity of Holocene climate as reconstructed from a Greenland ice core: Science, 270, 1962-1964, doi: 10.1126/science 270.5244.1962.

Peters, G. P., S. Anandakrishnan, R. B. Alley, and D. E. Voigt, 2012, Seismic attenuation in glacial ice: A proxy for englacial temperature: Journal of Geophysical Research, 117, F02008, doi: 10.1029/2011JF002201.

Rasmussen, S. O., P. M. Abbott, T. Blunier, A. J. Bourne, E. Brook, S. L. Buchardt, C. Buizert, J. Chappellaz, H. B. Clausen, E. Cook, D. DahlJensen, S. M. Davies, M. Guillevic, S. Kipfstuhl, T. Laepple, I. K. Seierstad, J. P. Severinghaus, J. P. Steffensen, C. Stowasser, A. Svensson, P. Vallelonga, B. M. Vinther, F. Wilhelms, and M. Winstrup, 2013, A first chronology for the North Greenland Eemian ice drilling (NEEM) ice core: Climate of the Past, 9, 2713-2730, doi: 10.5194/cp-9-2713-2013.

Rignot, E., and P. Kanagaratnam, 2006, Changes in the velocity structure of the Greenland ice sheet: Science, 311, 986-990, doi: 10.1126/science .1121381.

Thomas, R. H., 2004, Force-perturbation analysis of recent thinning and acceleration of Jakobshavn Isbræ, Greenland: Journal of Glaciology, 50, 5766, doi: 10.3189/172756504781830321.

Thomsen, L., 1986, Weak elastic anisotropy: Geophysics, 51, 1954-1966, doi: $10.1190 / 1.1442051$.

Tonn, R., 1991, The determination of the seismic quality factor $Q$ from VSP data: A comparison of different computational methods: Geophysical Prospecting, 39, 1-27, doi: 10.1111/j.1365-2478.1991.tb00298.x.

Tsvankin, I., 2005, Seismic signatures and analysis of reflection data in anisotropic media: Colorado School of Mines Press.

Van der Veen, C. J., J. C. Plummer, and L. A. Stearns, 2011, Controls on the recent speed-up of Jakobshavn Isbræ, west Greenland: Journal of Glaciology, 57, 770-782, doi: 10.3189/002214311797409776.

Van der Veen, C. J., and I. M. Whillans, 1994, Development of fabric in ice: Cold Regions Science and Technology, 22, 171-195, doi: 10.1016/0165232X(94)90027-2.

Wang, Y., T. Thorsteinsson, J. Kipfstuhl, H. Miller, D. Dahl-Jensen, and H. Shoji, 2002, A vertical girdle fabric in the NorthGRIP deep ice core North Greenland: Annals of Glaciology, 35, 515-520, doi: 10.3189/ 172756402781817301. 